\title{
25 Research Soure \\ Risk and Prevalence of Fatty Liver Assessed in A Scientific Research Institute in Beijing
}

\author{
Shu-Gen Qu ( $\sim$ shugenju@wmu.edu.cn ) \\ Wenzhou Medical University \\ Hui-Qin Chen \\ School of Radiation Medicine and Protection, Medical College of Soochow University \\ Dong-Mei Li \\ Fangshan Branch of Beijing Nuclear Industry Hospital
}

\section{Research article}

Keywords: Fatty liver, Prevalence, Epidemiology, Scientific Research Institute

Posted Date: October 29th, 2020

DOI: https://doi.org/10.21203/rs.3.rs-97724/v1

License: (a) (i) This work is licensed under a Creative Commons Attribution 4.0 International License. Read Full License 


\section{Abstract}

Background: To investigate the prevalence and distribution of employees with fatty liver disease (FLD) and assess the risk factors associated with diseases and biochemical markers.

Methods: Disease risk markers, and the levels of biochemical markers of 2541 participants from an Institute of Scientific Research in Beijing, were assessed according to standard methods and FLD was diagnosed by abdominal ultrasonography. Chi-square test was used to compare the results between participants with and without FLD.

Results: The prevalence of FLD, based on abdominal ultrasonography examination, was 43.5\% (1105/2541) in this population. The overall prevalence increased with age, and it was substantially higher in males $(50.0 \% \mathrm{vs}$ females: $34.6 \%, P<0.001)$. The gender and age distributions were significantly different between the two groups $\left(\chi^{2}=59.8\right.$ for gender and $t=-15.2$ for age or $\chi^{2}=205.6$ for age group, $\left.P<0.05\right)$. Chi-square test results revealed statistically significant differences in the BMI, prehypertension, hypertension, prediabetes, diabetes, hyperlipidemia, mixed type hyperlipidemia, hypertriglyceridemia, and the rise of GGT, ALT, AST, total bilirubin and indirect bilirubin between populations with and without FLD $(P<0.05)$. The risk of disease and biochemical markers contributing to the development of FLD was assessed by calculating the odd ratio (OR) and 95\% confidence interval $(95 \% \mathrm{Cl})$, and the results are ordered as follows: overweight and obesity [6.85 (5.54-8.48)], diabetes [6.00 (3.66-9.82)], prediabetes [5.06 (3.10-8.26)], ALT rise [4.67 (3.58-6.10)], GGT rise [4.01 (3.03-5.30)]. Multiple factors analysis was conducted to further compare those identified risk factors of FLD, which showed statistically significant differences in age, overweight and obesity, prediabetes, diabetes, mixed type hyperlipidemia, hypertriglyceridemia and ALT rise by Logistic regression analysis $(P<0.05)$.

Conclusions: Chronic disease, especially FLD, can be easily ignored during health assessment, although it is as important health risk factor as overweight and obesity, hypertension and diabetes. Physical examination is a practical approach to detect FLD in the process of control and prevention.

\section{Background}

Fatty liver disease (FLD) has become one of the most common disorders of liver since the improvement of people's living conditions and adoption of a more westernized diet. The prevalence of FLD has consistently risen over the recent years in China, especially for non-alcoholic fatty liver disease (NAFLD) which is associated with a higher energy intake and normal metabolic profile in patients with a genetic predisposition. In western countries, the prevalence of FLD in the adult population is estimated to be $20 \%-33 \%{ }^{[1]}$, increasing the importance for its clinical diagnosis ${ }^{[2,3]}$. FLD is typically diagnosed by imaging and ultrasonography at present, and is highly prevalent $(27 \%)$ in the urban population in China, with $7.6 \%-34.2 \%$ being young people. It is mainly related to obesity and metabolic syndrome (MetS) ${ }^{[4,5]}$. The hepatitis disease, initially found to be induced by hepatitis virus, is still a leading cause of chronic liver disease in China, even though viral hepatitis infection has decreased from 10-7\% between 1992 and 2006 in mainland China [6], and infectious hepatitis is an important factor leading to hepatocellular carcinoma. While as a visible and most frequently diagnosed liver disease in Chinese clinics, FLD represents a particularly alarming threat to human health and public healthcare system, especially because it can readily progress to steatohepatitis, fibrosis or cirrhosis, even liver cancer. Approximately $10 \%-25 \%$ of patients with silent liver disease develop non-alcoholic steatohepatitis (NASH), and 5\% - 8\% may develop liver cirrhosis 
within 5 years from diagnosis ${ }^{[7,8]}$, as well as having an increased risk to develop cardiovascular diseases and diabetes. Furthermore, $12.8 \%$ of patients with liver cirrhosis may develop hepatocellular carcinoma (HCC) within 3 years from diagnosis ${ }^{[9,10]}$. NASH is considered to be a major inducer of cryptogenic cirrhosis as patients with NASH have $70 \%$ risk to develop NAFLD $[11,12]$.

Because of the youth oriented tendency of FLD and the increased concern of scientific researchers for their health due to the high technology mastering demands in their working environment, it was imperative to assess the health of employees in an institute of scientific research in China. To gain further information on the prevalence and risk of fatty liver, the current study was designed to analyze the retrospective data of adult participants in a research institute in Beijing, based on physical examinations.

\section{Methods}

\section{Study participants}

A total number of 2760 consecutive adult workers who underwent routine physical examinations at the Fangshan Branch of Beijing Nuclear Industry Hospital from September 1, 2018 to December 31, 2018 were retrospectively enrolled in the study.

\section{Physical examination, biochemical and radiological analysis}

The physical examination was performed by a professional personnel doctor who had the title of attending or above. The routine examinations of internal medicine, surgery and ophthalmology were carried out according to the unified standards. Patients were presented to the hospital for blood sampling in the morning after $10 \mathrm{~h}$ of fasting. All serological measurements were performed on-site at the certified laboratory. Unicel DxC 800 automatic biochemistry analyzer (Beckman Coulter Laboratories, United States) was used for the determination of plasma concentration of glucose, total cholesterol (TC), triglyceride (TG), low density lipoprotein cholesterol (LDL-C), gamma glutamyl transpeptidase (GGT), alanine aminotransferase (ALT), aspartate aminotransferase (AST), total bilirubin (TBIL), direct bilirubin (DBIL), indirect bilirubin (IBIL) and other biochemical markers. Abdominal ultrasonography was conducted to detect FLD with standard imaging criteria ${ }^{[13]}$. Electrocardiography and chest Xray were performed to rule out serious heart and lung diseases. Hepatitis B test in serum was performed to excludes HBV/HCV chronic infections. All employee were excluded from acute infection during physical examination.

\section{Diagnostic criteria and definitions}

The participants were allocated into 4 groups according to their Body mass index (BMI): thin ( $\left.\leq 18.4 \mathrm{~kg} / \mathrm{m}^{2}\right)$, normal $\left(18.5-23.9 \mathrm{~kg} / \mathrm{m}^{2}\right)$, overweight $\left(24.0-27.9 \mathrm{~kg} / \mathrm{m}^{2}\right)$ and obese $\left(\geq 28.0 \mathrm{~kg} / \mathrm{m}^{2}\right)^{[14,15]}$. According to the Chinese and national hypertension guidelines for the management of hypertension ${ }^{[16,17]}$, hypertension was diagnosed when the systolic pressure was $\geq 140 \mathrm{mmHg}$ and/or the diastolic pressure was $\geq 90 \mathrm{mmHg}$; prehypertension was diagnosed when the systolic pressure was $120-139 \mathrm{mmHg}$ and/or the diastolic pressure was $80-89 \mathrm{mmHg}$ under no medication and no self-reported hypertension. Hyperglycemia was diagnosed when the fasting plasma glucose levels were 6.1-6.95 $\mathrm{mmol} / \mathrm{L}$ for prediabetes, and $\geq 6.95 \mathrm{mmol} / \mathrm{L}$ for diabetes when

patients were receiving medication or had reported diabetes ${ }^{[18,19]}$. Dyslipidemia was defined when the cholesterol TC levels were $\geq 5.7 \mathrm{mmol} / \mathrm{L}$ and/or TG $\geq 1.8 \mathrm{mmol} / \mathrm{L}$ and/or LDL-C $\geq 3.6 \mathrm{mmol} / \mathrm{L}$ and/or HDL-C $<0.8 \mathrm{mmol} / \mathrm{L}$ 
[20]. The various types of hyperlipidemia were diagnosed when TC content was $\geq 5.7 \mathrm{mmol} / \mathrm{L}$ and TG $\geq$ $1.8 \mathrm{mmol} / \mathrm{L}$ for mixed type hyperlipidemia, when TC levels were $\geq 5.7 \mathrm{mmol} / \mathrm{L}$ and $\mathrm{TG}<1.8 \mathrm{mmol} / \mathrm{L}$, and when LDL-C $<3.6 \mathrm{mmol} / \mathrm{L}$ and HDL-C $\geq 0.8 \mathrm{mmol} / \mathrm{L}$ for hypercholesterolemia, when the TC content was $<5.7 \mathrm{mmol} / \mathrm{L}$ and $T G \geq 1.8 \mathrm{mmol} / \mathrm{L}$, and when LDL-C levels were $<3.6 \mathrm{mmol} / \mathrm{L}$ and $\mathrm{HDL}-\mathrm{C} \geq 0.8 \mathrm{mmol} / \mathrm{L}$ for hypertriglyceridemia, and when TC concentration was $<5.7 \mathrm{mmol} / \mathrm{L}$ and $\mathrm{TG} \geq 1.8 \mathrm{mmol} / \mathrm{L}$ and LDL-C $\geq$ $3.6 \mathrm{mmol} / \mathrm{L}$ and $\mathrm{HDL}-\mathrm{C}<0.8 \mathrm{mmol} / \mathrm{L}$ for low density lipoprotein cholesterolemia. Abnormal elevation in the levels of gamma glutamyl transpeptidase (GGT), alanine aminotransferase (ALT), aspartate aminotransferase (AST), total bilirubin (TBIL), direct bilirubin (DBIL) and indirect bilirubin (IBIL) were defined when these were $\geq 50 \mathrm{U} / \mathrm{L}, \geq$ $40 \mathrm{U} / \mathrm{L}, \geq 40 \mathrm{U} / \mathrm{L}, \geq 20 \mu \mathrm{mol} / \mathrm{L}, \geq 6 \mu \mathrm{mol} / \mathrm{L}$ and $\geq 15 \mu \mathrm{mol} / \mathrm{L}$, respectively.

\section{Statistical analysis}

The participants' physical examination results were stored in the database of the health center management system (Peking University Medical Information Technology Co., Ltd), and exported as an excel spreadsheet to extract the relevant data. All statistical analyses were performed using the SPSS statistical software suite (version 20.0, Chicago, IL, United States). Measurement data were expressed as mean \pm SD. Comparisons between quantitative data and categorical variables were carried out by Student's $t$-test and $\chi^{2}$ test, respectively.

Odds ratio (OR) was used to express ratio between positive to negative in FLD group and positive to negative in Non-FLD group. i.e. OR=(positive/negative in FLD group)/(positive/negative in Non-FLD group). Regression models was used to evaluate the relations between risk factors and FLD morbidity from specific causes by adjusting the confounding factors. In this study, multivariate analysis with statistically significant risk factors by Chi-square test at univariate model was performed by Logistic regression analysis. All reported $P$-values were twosided, and differences with $P<0.05$ were considered statistically significant.

\section{Results}

\section{Demographics and distribution of fatty liver}

The study population of physical examination of employees in the institute of scientific research of Beijing comprised 1466 males and 1075 females besides 19 of having HBV/HCV inflections, 12 of lung shadow, 32 of fibroid, 9 of influenza and 147 of missing. The average age of participants was $39.4 \pm 9.4$ years old (range: 1960 years) and they were divided to four groups, each with a ten years coverage. The percentage of FLD was $43.5 \%$ based on abdominal ultrasonography (1105/2541), with an obvious higher prevalence in males than in females (50.0\% vs 34.6\%, $P<0.001)$. As presented in Table 1, the prevalence of FLD was much higher in males than in females $(65.7 \%$ vs $34.3 \%$ in the 30 to 39 year-old group, and $57.1 \%$ vs $41.7 \%$ in the 40 to 49 year-old group), and this trend did not exist in the other two age groups (for both $P<0.001, \chi^{2}=205.6$ ) (shown in Table 1). 
Table 1

Age and gender distribution of overall fatty liver prevalence and total populations (\%)

\begin{tabular}{|c|c|c|c|c|c|c|}
\hline Age & Total Populations & Positive in populations & In males & In females & $\chi^{2}$ & $P$ \\
\hline $19-29$ & 429 & $89(20.7)$ & $51(57.3)$ & $38(42.7)$ & 2.2 & 0.141 \\
\hline $30-39$ & 953 & $367(38.5)$ & $241(65.7)$ & $126(34.3)$ & 18.4 & $<0.001$ \\
\hline $40-49$ & 751 & $375(49.9)$ & $230(61.3)$ & $145(38.7)$ & 17.7 & $<0.001$ \\
\hline $50-60$ & 408 & $274(67.2)$ & $211(77.0)$ & $63(23.0)$ & 2.7 & 0.098 \\
\hline Total & 2541 & $1105(43.5)$ & $733(66.3)$ & $372(33.7)$ & 59.8 & $<0.001$ \\
\hline
\end{tabular}

1105 participants were diagnosed with FLD by physical examination. The incidence of all the markers basically showed an obvious increase in the FLD group when compared with the non-FLD and total study population. The top five strongest markers consisted of four disease and six biochemical markers and its morbidity rate are listed in order as follows in total and FLD populaitons: overweight and obesity ( $47.5 \%$ vs $27.7 \%$ vs $72.4 \%$ ), prehypertension ( $47.1 \%$ vs $49.1 \%$ vs $44.7 \%$ ), hyperlipidemia (33.3\% vs $20.7 \%$ vs $49.8 \%$ ), hypertension $(27.2 \%$ vs $17.8 \%$ vs $39.1 \%$ ), hypertriglyceridemia ( $14.2 \%$ vs $7.1 \%$ vs $23.5 \%$ )(shown in Table 2 ). 
Table 2

Prevalence and categorization in the total study population (\%)

\begin{tabular}{|c|c|c|c|c|c|c|}
\hline \multirow[t]{2}{*}{ Markers } & \multicolumn{2}{|c|}{ Total populations } & \multicolumn{2}{|c|}{ FLD populations } & \multicolumn{2}{|c|}{ Non-FLD population } \\
\hline & No. & Positive No. & No. & Positive No. & No. & Positive No. \\
\hline Fatty liver & 2541 & 1105(43.5) & 1105 & $1105(100)$ & 1436 & $0(0.00)$ \\
\hline Overweight and above & 1718 & $816(47.5)$ & 761 & $551(72.4)$ & 957 & 265(27.7) \\
\hline Prehypertension & 2346 & 1106(47.1) & 1030 & $460(44.7)$ & 1316 & $646(49.1)$ \\
\hline Hypertension & 2346 & $637(27.2)$ & 1030 & $403(39.1)$ & 1316 & $234(17.8)$ \\
\hline Prediabetes & 2498 & $98(3.9)$ & 1085 & $77(7.1)$ & 1413 & $21(1.5)$ \\
\hline Diabetes & 2498 & $106(4.2)$ & 1085 & $86(7.9)$ & 1413 & $20(1.5)$ \\
\hline Hyperlipidemia & 2497 & $831(33.3)$ & 1083 & $539(49.8)$ & 1414 & 292(20.7) \\
\hline Mixed type hyperlipidemia & 2497 & $179(7.2)$ & 1083 & $141(13.0)$ & 1414 & $38(2.7)$ \\
\hline Hypercholesterolemia & 2497 & $45(1.8)$ & 1083 & $16(1.5)$ & 1414 & $29(2.1)$ \\
\hline Hypertriglyceridemia & 2497 & $355(14.2)$ & 1083 & $255(23.5)$ & 1414 & $100(7.1)$ \\
\hline LDL cholesterolemia & 2497 & $33(1.3)$ & 1083 & $13(1.2)$ & 1414 & $20(1.4)$ \\
\hline GGT rise & 2501 & $274(11.0)$ & 1086 & 199(18.3) & 1415 & $75(5.3)$ \\
\hline ALT rise & 2501 & $321(12.8)$ & 1086 & $240(22.1)$ & 1415 & $81(5.7)$ \\
\hline AST rise & 2501 & $99(4.0)$ & 1086 & $66(6.1)$ & 1415 & $33(2.3)$ \\
\hline Total bilirubin & 2501 & $336(13.4)$ & 1086 & $129(11.9)$ & 1415 & 207(14.6) \\
\hline Direct bilirubin & 2499 & $285(11.4)$ & 1084 & $111(10.2)$ & 1415 & $174(12.3)$ \\
\hline Indirect bilirubin & 1468 & 177(12.1) & 658 & $63(9.6)$ & 810 & 114(14.1) \\
\hline
\end{tabular}

\section{Gender and age distribution of participants diagnosed with fatty liver}

The gender distribution of prevalence and categorization of the 1105 participants with FLD is listed in Table 3 . The prevalence of FLD was relatively higher in males than females for most of the markers apart from prehypertension and hypercholesterolemia (overweight and obesity: $81.4 \%$ vs $54.2 \%$; hypertension: $46.2 \%$ vs $23.9 \%$; hyperlipidemia: 57.7\% vs $34.0 \%$; hypertriglyceridemia: $29.1 \%$ vs $12.4 \%$; GGT rise: $24.6 \%$ vs $5.8 \%$; ALT rise: $28.9 \%$ vs $8.5 \%$; TBIL: $15.8 \%$ vs $4.1 \%$; DBIL: $13.6 \%$ vs $3.6 \%$; IBIL: $13.3 \%$ vs $2.3 \%$; prediabetes: $8.6 \%$ vs $4.1 \%$; diabetes: $9.8 \%$ vs $4.1 \%$ ). However, the incidence was lower for prehypertension and hypercholesterolemia in males than in females (prehypertension: $42.9 \%$ vs $48.5 \%$; hypercholesterolemia: $1.0 \%$ vs $2.5 \%$ ) in the FLD group. The first top five ranking markers were overweight and obesity, hyperlipidemia, hypertension, prehypertension and hypertriglyceridemia for 
males, and overweight and obesity, prehypertension, hyperlipidemia, hypertension and hypertriglyceridemia for females.

Table 3

Gender distribution of prevalence and categorization in the 1105 fatty liver populations (\%)

\begin{tabular}{|c|c|c|c|c|c|c|}
\hline \multirow{3}{*}{$\begin{array}{l}\text { Markers } \\
\text { Overweight and above }\end{array}$} & \multirow{2}{*}{\multicolumn{2}{|c|}{$\begin{array}{l}\text { Populations in males } \\
\text { Examined Positive }\end{array}$}} & \multirow{2}{*}{\multicolumn{2}{|c|}{$\begin{array}{l}\text { Populations in females } \\
\text { Examined Positive }\end{array}$}} & \multirow{3}{*}{$\begin{array}{l}x^{2} \\
62.2\end{array}$} & \multirow{3}{*}{$\begin{array}{l}P \\
<0.001\end{array}$} \\
\hline & & & & & & \\
\hline & 510 & $415(81.4)$ & 251 & $136(54.2)$ & & \\
\hline Prehypertension & 704 & $302(42.9)$ & 326 & $158(48.5)$ & 2.8 & 0.095 \\
\hline Hypertension & 704 & $325(46.2)$ & 326 & $78(23.9)$ & 46.3 & $<0.001$ \\
\hline Prediabetes & 722 & $62(8.6)$ & 363 & $15(4.1)$ & 7.3 & 0.007 \\
\hline Diabetes & 722 & $71(9.8)$ & 363 & $15(4.1)$ & 10.8 & 0.001 \\
\hline Hyperlipidemia & 721 & $416(57.7)$ & 362 & 123(34.0) & 54.2 & $<0.001$ \\
\hline Mixed type hyperlipidemia & 721 & $59(8.2)$ & 362 & $18(5.0)$ & 3.8 & 0.052 \\
\hline Hypercholesterolemia & 721 & $7(1.0)$ & 362 & $9(2.5)$ & 3.8 & 0.051 \\
\hline Hypertriglyceridemia & 721 & $210(29.1)$ & 362 & $45(12.4)$ & 37.3 & $<0.001$ \\
\hline LDL cholesterolemia & 721 & $10(1.4)$ & 362 & $3(0.8)$ & 0.3 & 0.617 \\
\hline GGT rise & 723 & $178(24.6)$ & 363 & $21(5.8)$ & 57.3 & $<0.001$ \\
\hline ALT rise & 723 & 209(28.9) & 363 & $31(8.5)$ & 58.2 & $<0.001$ \\
\hline AST rise & 723 & $48(6.6)$ & 363 & $18(5.0)$ & 1.2 & 0.274 \\
\hline Total bilirubin & 723 & $114(15.8)$ & 363 & $15(4.1)$ & 31.3 & $<0.001$ \\
\hline Direct bilirubin & 722 & $98(13.6)$ & 362 & $13(3.6)$ & 26.1 & $<0.001$ \\
\hline Indirect bilirubin & 437 & $58(13.3)$ & 221 & $5(2.3)$ & 20.6 & $<0.001$ \\
\hline
\end{tabular}

The age prevalence distribution of diseases and biochemical markers in the 1105 participants with FLD is displayed in Table 4. The overall prevalence increased with age, which was statistically significant different for all disease markers and for two of the biochemical markers (hyperlipidemia and ALT rise), and there was no age bias. However, the prevalence of ALT rise decreased prominently with age $(28.4-28.3 \%$ to $20.5-13.8 \%, P<0.05)$. 
Table 4

Age distribution of prevalence and categorization in the 1105 fatty liver populations (\%)

\begin{tabular}{|c|c|c|c|c|c|c|c|}
\hline Markers & $\begin{array}{l}\text { Populations } \\
\text { examined }\end{array}$ & $19-29$ & $30-39$ & $40-49$ & $50-60$ & $x^{2}$ & $P$ \\
\hline $\begin{array}{l}\text { Overweight and } \\
\text { above }\end{array}$ & $48: 245: 274: 194$ & $28(58.3)$ & 188(76.7) & 187(68.2) & 148(76.3) & 10.9 & 0.012 \\
\hline Prehypertension & $76: 341: 352: 261$ & $38(50.0)$ & 159(46.6) & 167(47.4) & $96(36.8)$ & 9.1 & 0.028 \\
\hline Hypertension & $76: 341: 352: 261$ & $23(30.3)$ & 108(31.7) & $140(39.8)$ & $132(50.6)$ & 24.9 & $\stackrel{<}{0.001}^{<}$ \\
\hline Prediabetes & $88: 364: 365: 268$ & $2(2.3)$ & $14(3.8)$ & $29(7.9)$ & $32(11.9)$ & 18.9 & $\begin{array}{l}< \\
0.001\end{array}$ \\
\hline Diabetes & $88: 364: 365: 268$ & $4(4.5)$ & $11(3.0)$ & $34(9.3)$ & $37(13.8)$ & 27.0 & $\begin{array}{l}<.001 \\
0.001\end{array}$ \\
\hline Hyperlipidemia & $88: 364: 363: 268$ & $32(36.4)$ & $162(44.5)$ & $184(50.7)$ & $161(60.1)$ & 21.9 & $\hat{0}_{0.001}$ \\
\hline $\begin{array}{l}\text { Mixed type } \\
\text { hyperlipidemia }\end{array}$ & $88: 364: 363: 268$ & $9(10.2)$ & $39(10.7)$ & $48(13.2)$ & $45(16.7)$ & 5.6 & 0.133 \\
\hline Hypercholesterolemia & $88: 364: 363: 268$ & $2(2.3)$ & $4(1.1)$ & $3(0.8)$ & $7(2.6)$ & 3.9 & 0.271 \\
\hline Hypertriglyceridemia & $88: 364: 363: 268$ & $13(14.8)$ & $80(22.0)$ & $93(25.6)$ & $69(25.7)$ & 5.8 & 0.119 \\
\hline LDL cholesterolemia & $88: 364: 363: 268$ & $1(1.1)$ & $4(1.1)$ & $5(1.4)$ & $3(1.1)$ & 0.1 & 0.986 \\
\hline GGT rise & $88: 364: 365: 269$ & $13(14.8)$ & $59(16.2)$ & $75(20.5)$ & $52(19.3)$ & 3.2 & 0.359 \\
\hline ALT rise & $88: 364: 365: 269$ & $25(28.4)$ & $103(28.3)$ & $75(20.5)$ & $37(13.8)$ & 21.5 & $\begin{array}{l}< \\
0.001\end{array}$ \\
\hline AST rise & $88: 364: 365: 269$ & $7(8.0)$ & $26(7.1)$ & $23(6.3)$ & $10(3.7)$ & 3.9 & 0.270 \\
\hline Total bilirubin & $88: 364: 365: 269$ & 12(13.6) & $38(10.4)$ & $43(11.8)$ & $36(13.4)$ & 1.6 & 0.667 \\
\hline Direct bilirubin & $88: 364: 365: 269$ & $11(12.5)$ & $33(9.1)$ & $39(10.7)$ & $28(10.4)$ & 1.1 & 0.767 \\
\hline Indirect bilirubin & 47:191:235:185 & $5(10.6)$ & $14(7.3)$ & $28(11.9)$ & $16(8.6)$ & 2.8 & 0.416 \\
\hline
\end{tabular}

Comparison of the fatty liver to the non-fatty liver control group revealed gender and age distribution differences $\left(\chi^{2}=59.8\right.$ for gender and $t=-15.2$ for age or $\chi^{2}=205.6$ for age group, $\left.P<0.05\right)$, therefore we analyzed the odds ratio (OR) to identify the risk factors associated with FLD. The Chi-square test was performed to assess factors such as BMI, prehypertension, hypertension, prediabetes, diabetes, hyperlipidemia, mixed type hyperlipidemia, hypertriglyceridemia, and the rise of GGT, ALT, AST, total bilirubin and indirect bilirubin between populations with and without FLD $(P<0.05)$. The values of OR and $95 \%$ confidence interval $(95 \% \mathrm{Cl})$ are listed in a descending order in Table 5, starting with overweight and obesity, diabetes, prediabetes, ALT rise, GGT rise and so on. 
Table 5

Comparison of prevalence of risk factors between with and without fatty liver (\%).

\begin{tabular}{|c|c|c|c|c|c|c|c|c|}
\hline \multirow[t]{2}{*}{ Markers } & \multicolumn{2}{|c|}{$\begin{array}{l}\text { Populations with fatty } \\
\text { liver }\end{array}$} & \multicolumn{2}{|c|}{$\begin{array}{l}\text { Populations without } \\
\text { fatty liver }\end{array}$} & \multirow[t]{2}{*}{ OR } & \multirow[t]{2}{*}{$95 \% \mathrm{Cl}$} & \multirow[t]{2}{*}{$x^{2}$} & \multirow[t]{2}{*}{$P$} \\
\hline & Examined & Positive & Examined & Positive & & & & \\
\hline $\begin{array}{l}\text { Overweight and } \\
\text { above }\end{array}$ & 761 & $551(72.4)$ & 957 & $265(27.7)$ & 6.85 & $\begin{array}{l}5.54 \\
\tilde{8} .48\end{array}$ & 339.9 & $<0.001$ \\
\hline Prehypertension & 1030 & $460(44.7)$ & 1316 & $646(49.1)$ & 0.84 & $\begin{array}{l}0.71 \\
\tilde{0} \\
0.99\end{array}$ & 4.5 & 0.033 \\
\hline Hypertension & 1030 & 403(39.1) & 1316 & $234(17.8)$ & 2.97 & $\begin{array}{l}2.46 \\
\tilde{3} .59\end{array}$ & 133.1 & $<0.001$ \\
\hline Prediabetes & 1085 & 77(7.1) & 1413 & $21(1.5)$ & 5.06 & $\begin{array}{l}3.10 \\
\tilde{8} \\
8.26\end{array}$ & 51.3 & $<0.001$ \\
\hline Diabetes & 1085 & $86(7.9)$ & 1413 & $20(1.4)$ & 6.00 & $\begin{array}{l}3.66 \\
\tilde{9} \\
9.82\end{array}$ & 64.0 & $<0.001$ \\
\hline Hyperlipidemia & 1083 & $539(49.8)$ & 1414 & $292(20.7)$ & 3.81 & $\begin{array}{l}3.20 \\
\tilde{4} .54\end{array}$ & 234.2 & $<0.001$ \\
\hline $\begin{array}{l}\text { Mixed type } \\
\text { hyperlipidemia }\end{array}$ & 1083 & $141(13.0)$ & 1414 & $38(2.7)$ & 5.41 & $\begin{array}{l}3.74 \\
\tilde{\sim} \\
7.81\end{array}$ & 98.1 & $<0.001$ \\
\hline Hypercholesterolemia & 1083 & $16(1.5)$ & 1414 & $29(2.1)$ & 0.72 & $\begin{array}{l}0.39 \\
\tilde{1} \\
1.33\end{array}$ & 1.1 & 0.286 \\
\hline Hypertriglyceridemia & 1083 & $255(23.5)$ & 1414 & $100(7.1)$ & 4.05 & $\begin{array}{l}3.16 \\
\tilde{5} .18\end{array}$ & 136.5 & 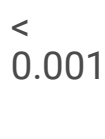 \\
\hline LDL cholesterolemia & 1083 & $13(1.2)$ & 1414 & $20(1.4)$ & 0.85 & $\begin{array}{l}0.42 \\
\tilde{1} \\
1.71\end{array}$ & 0.2 & 0.643 \\
\hline GGT rise & 1086 & 199(18.3) & 1415 & $75(5.3)$ & 4.01 & $\begin{array}{l}3.03 \\
\tilde{5} .30\end{array}$ & 106.8 & $<0.001$ \\
\hline ALT rise & 1086 & $240(22.1)$ & 1415 & $81(5.7)$ & 4.67 & $\begin{array}{l}3.58 \\
\tilde{6} .10\end{array}$ & 147.3 & $<0.001$ \\
\hline AST rise & 1086 & $66(6.1)$ & 1415 & $33(2.3)$ & 2.71 & $\begin{array}{l}1.77 \\
\tilde{4} .15\end{array}$ & 22.7 & $<0.001$ \\
\hline Total bilirubin & 1086 & $129(11.9)$ & 1415 & $207(14.6)$ & 0.79 & $\begin{array}{l}0.62 \\
\tilde{1} \\
1.00\end{array}$ & 4.0 & 0.046 \\
\hline
\end{tabular}




\begin{tabular}{|c|c|c|c|c|c|c|c|c|}
\hline \multirow[t]{2}{*}{ Markers } & \multicolumn{2}{|c|}{$\begin{array}{l}\text { Populations with fatty } \\
\text { liver }\end{array}$} & \multicolumn{2}{|c|}{$\begin{array}{l}\text { Populations without } \\
\text { fatty liver }\end{array}$} & \multirow[t]{2}{*}{ OR } & \multirow[t]{2}{*}{$95 \% \mathrm{Cl}$} & \multirow[t]{2}{*}{$x^{2}$} & \multirow[t]{2}{*}{$P$} \\
\hline & Examined & Positive & Examined & Positive & & & & \\
\hline Direct bilirubin & 1084 & 111(10.2) & 1415 & $174(12.3)$ & 0.81 & $\begin{array}{l}0.63 \\
\tilde{\sim} \\
1.05\end{array}$ & 2.6 & 0.109 \\
\hline Indirect bilirubin & 658 & $63(9.6)$ & 810 & $114(14.1)$ & 0.65 & $\begin{array}{l}0.47 \\
\tilde{\tilde{0}} \\
0.90\end{array}$ & 6.9 & 0.008 \\
\hline
\end{tabular}

Multiple factors regression analysis was carried out to compare the risk factors of FLD which displayed significant difference by single factor Chi-square test analysis, and the corresponding results are shown in Table 6. Logistic regression analysis revealed that there were statistically significant differences in age, overweight and obesity, prediabetes, diabetes, mixed type hyperlipidemia, hypertriglyceridemia and ALT rise $(P<0.05)$.

Table 6

Multiple Logistics regression analysis of risk factors for fatty liver

\begin{tabular}{|lllllll|}
\hline Markers & B & Std. Error & Wald & Sig. & Exp(B) & $95 \%$ Cl for Exp(B) \\
\hline Gender & -0.309 & 0.186 & 2.775 & 0.096 & 0.734 & $0.510 \sim 1.056$ \\
\hline Age & 0.066 & 0.010 & 46.101 & 0.000 & 1.069 & $1.048 \sim 1.089$ \\
\hline Overweight and above & -1.579 & 0.178 & 78.440 & 0.000 & 0.206 & $0.145 \sim 0.292$ \\
\hline Prehypertension & -0.013 & 0.207 & 0.004 & 0.949 & 0.987 & $0.658 \sim 1.480$ \\
\hline Hypertension & -0.396 & 0.233 & 2.878 & 0.090 & 0.673 & $0.426 \sim 1.063$ \\
\hline Prediabetes & -1.596 & 0.557 & 8.213 & 0.004 & 0.203 & $0.068 \sim 0.604$ \\
\hline Diabetes & -1.161 & 0.501 & 5.366 & 0.021 & 0.313 & $0.117 \sim 0.836$ \\
\hline Hyperlipidemia & -0.029 & 0.242 & 0.014 & 0.906 & 0.972 & $0.605 \sim 1.562$ \\
\hline Mixed type hyperlipidemia & -1.209 & 0.411 & 8.656 & 0.003 & 0.298 & $0.133 \sim 0.668$ \\
\hline Hypertriglyceridemia & 10.759 & 0.300 & 6.398 & 0.011 & 0.468 & $0.260 \sim 0.843$ \\
\hline GGT rise & 0.192 & 0.279 & 0.470 & 0.493 & 1.211 & $0.700 \sim 2.094$ \\
\hline ALT rise & -0.968 & 0.288 & 11.296 & 0.001 & 0.380 & $0.216 \sim 0.668$ \\
\hline AST rise & -0.674 & 0.450 & 2.245 & 0.134 & 0.510 & $0.211 \sim 1.231$ \\
\hline Total bilirubin & -0.765 & 0.664 & 1.328 & 0.249 & 0.465 & $0.127 \sim 1.710$ \\
\hline Indirect bilirubin & 1.216 & 0.688 & 3.126 & 0.077 & 3.374 & $0.876 \sim 12.995$ \\
\hline Constant & 3.732 & 1.133 & 10.852 & 0.001 & 41.752 & - \\
\hline
\end{tabular}

\section{Discussion}


FLD is a common clinical pathologic syndrome that manifests from hepatic steatosis and excessive fat accumulation induced by a variety of factors. Despite the increase in alcohol sales in China, the intake of alcohol in public institutions has been significantly reduced by government policies. However, NAFLD is still prevalent and is strongly associated with metabolic disorders. Not surprisingly, FLD has been frequently reported in patients with type 2 diabetes mellitus (T2DM) and obesity, accounting for $40-80 \%$ and $30-90 \%$, respectively ${ }^{[21]}$. Thus it is necessary to track FLD progress as it may develop to steatohepatitis, fatty liver cirrhosis, and associated virus hepatocellular carcinoma. Although liver biopsy is the gold standard for the diagnosis of FLD, abdomen ultrasonography is still a general approach to screen FLD especially in adult populations. The prevalence of NAFLD has increased globally and recently became the predominant cause of chronic liver disease around the world. The epidemiology and demographic characteristics vary worldwide ${ }^{[3]}$. The incidence rate of FLD, diagnosed by ultrasonography, was reported to be more than $46 \%$ in developed countries ${ }^{[7,22,23]}$ and $39.5 \%$ in developing countries ${ }^{[4,24]}$, and it is still on the rise.

In the current study in Fangshan Branch of the Beijing Nuclear Industry Hospital, the prevalence of FLD was 43.5\%, which was higher than the results reported by another survey study in Beijing ${ }^{[24]}$. However, only 19 to 60 -year-old subjects were employed in the research and $17.9 \%$ of patients below 40-year-old were diagnosed with FLD (16.1\% is the standard). The prevalence increased with age, which was dramatically higher than previously estimated values in other Chinese cities ${ }^{[25,26]}$. Overall, the age group with the highest FLD prevalence was the over 50-yearold group [27], at which age the adiponectin levels in women also generally decreased. According to the results shown in Table 1, there was a negative correlation between FLD prevalence and adiponectin levels, which could explain the lower incidence of FLD in women over 50-year-old as at this age they undergo menopause and as a result have lower estrogen and higher androgen levels. As a whole, the prevalence of FLD, overweight and obove, prehypertension (hypertension) and hyperlipidemia was relatively high in the total population (Table 2). Actually, age comes with experience and higher responsibility in the working environment. Intense competition for title assessment and promotion and the prolonged working hours in this institute has resulted in the personnel to decrease physical activity time, leading to the prevalence of overweight and obesity and hypertension, which are risk factors for developing FLD with diabetes ${ }^{[3,11,20,24]}$. The westernized diet, irregular diet, reduced physical exercise, hypertension and diabetes are major determinants of FLD among Chinese scientific researchers. The incidence of overweight and obesity, hypertension and diabetes was considerably high in the 1105 participants diagnosed with FLD. As seen in the Table 2, the prevalence of the other biochemical markers was consistent with that of disease markers, and both resembled that of hyperlipidemia and FLD.

Previous reports have indicated that males have more risk to develop FLD than females after the age of 50 [28]. However, alcohol-related FLD (AFLD) in males is more prominent than in females under excessive alcohol consumption. In this research, AFLD and NAFLD were not separately investigated. The rate of rise of the levels of biochemical markers for MetS in males exceeded that of females, with the exception of AST. The prevalence of FLD was $50 \%$ in males and $34.6 \%$ in females, which was relatively higher than what has been reported in a previous Chinese study ${ }^{[29]}$. The results of gender distribution of prevalence and categorization in the 1105 participants with FLD (Table 3), were in agreement with the findings of a Japanese study ${ }^{[30]}$. Besides, males usually consume high fat diet and as a consequence store fat in their abdomen, whereas females that look after their weight tend to utilize fat in the subcutaneous tissue by weight loss plans such as physical exercise. The reason why the prevalence of overweight and obove was still high remains uncertain. The differential fat accumulation in males and females may be a consequence of their different lipid metabolism pathways. The

Page $11 / 16$ 
comparative values and distribution of different genders are listed in Table 3. Briefly, our study, along with previously published findings, highlights the importance of prevention and screening of FLD in specific age populations. It has been reported that a high protein and hypocaloric diet are associated with improved lipid profile, glucose homeostasis and liver enzymes function in NAFLD, independent to BMI decrease or body fat mass reduction ${ }^{[31]}$. However, our results showed statistically significant differences in all disease markers and two of the biochemical markers (hyperlipidemia and ALT rise) between the age groups in the FLD group. As shown in Table 4, the prevalence of prehypertension and ALT rise decreased by aging, and this rise was surprisingly higher in the 19 to 29 year-old group than in the other three groups. On the other hand, although the prevalence of other markers increased with age, there were no significant differences between the age groups.

In the current study most FLDs were diagnosed in participants without any clinical symptoms. Over $50 \%$ of cases with FLD had mildly increased contents of biochemical markers, most of which were also accompanied by a rise in cholesterol, triglyceride, LDL cholesterol, GGT, AST levels. There were significant differences in hyperlipidemia, mixed type hyperlipidemia, hypertriglyceridemia, GGT, AST and AST between the FLD and non-FLD group (Table 5). These alterations were found to be associated with certain disease markers. However, in this cohort study analysis of risk factors contributing to the prevalence of FLD was not performed. These results suggest that FLD, with NAFLD being the most common type, may be correlated with those disorders. Additionally, age and gender are basic risk factors as they play important roles in the development of NAFLD ${ }^{[32]}$. Multiple Logistic analysis was carried out to identify risk factors for the analysis of the prevalence of FLD. The vital risk factors determined in this study were: age, overweight and obesity, prediabetes, diabetes, mixed type hyperlipidemia, hypertriglyceridemia and ALT (Table 6). However, our study included a single-site population and diagnosis of FLD was based on ordinary physical examination, which may limit the application of the identified markers for screening larger populations. Therefore, further studies with higher number of participants from various institutes of scientific research, including more demographic and biochemical data, are required in the future.

Recently, FLD has also been attributed to NAFLD, which is characterized by a heightened systemic proinflammatory state. NAFLD accelerates the risks of arteriosclerosis and other cardiovascular diseases or associated events ${ }^{[33]}$. However, the previously reported correlation relationship between total cholesterol levels and cancer risk ${ }^{[34]}$ is controversial because in the current study we found that FLD prevalence was associated with other risk factors (e.g., gender, age, overweight and obesity, hypertension, diabetes and MetS), and NAFLD was closely related to the incidence of cardiovascular disease, a clear risk factor for hyperlipidemia [35]. The incidence and mortality rates of cardiovascular diseases were the highest amongst chronic diseases worldwide [36]. The most common causes of death by NAFLD are atherosclerotic cardiovascular diseases and hepatic cirrhosis ${ }^{[37]}$, hence it is important to regularly screen for FLD to prevent development of disease. The screening and prevention of obesity and hypertension are also of great importance, as they are risk factors of cardiovascular diseases and their prevalence was $39.1 \%$ and $7.9 \%$, respectively, in the FLD group. Therefore, more attention should be paid to systemic diseases of the cardiovascular, urinary, digestive and respiratory system during physical examination, instead of the incidence of overweight and obove, diabetes, hypertension and dyslipidemia.

\section{Conclusion}

high prevalence of FLD was discovered in employees of the institute of scientific research by physical examination, thus targeted intervention should be carried out as soon as possible. However, this study also has some shortcomings. First, the demographic information was relatively small; second,the diagnosed FLD had not 
reganding severity with mild, moderate and severe; besides, the level of AST and ALT is parallel, while in this study, the rise of ALT and AST was not similar; lastly, the incidence of pre-hypertension was too high in this study, more relative studies are needed to gain more detailed information for FLD in the general populations from other graduate schools and colleges to determine the contribution of the above risk factors to FLD development and to set up better guidelines for prevention and control of chronic diseases.

\section{Abbreviations}

gamma glutamyl transpeptidase (GGT), alanine aminotransferase (ALT), aspartate aminotransferase (AST), total bilirubin (TBIL), direct bilirubin (DBIL), indirect bilirubin (IBIL), total cholesterol (TC), triglyceride (TG), low density lipoprotein cholesterol (LDL-C), fatty liver disease (FLD), non-alcoholic fatty liver disease (NAFLD).

\section{Declarations}

There study was approvaled by the ethics committee of Soochow University.

\section{Ethics approval and consent to participate}

Not applicable.

\section{Funding}

The present study was supported by the Nuclear Energy Development Project (No. 2016-1295), and Postgraduate Research \& Practice Innovation Program of Jiangsu Province (KYCX17-2017).

\section{Availability of data and materials}

The datasets used and/or analysed during the current study available from the corresponding author on reasonable request.

\section{Author contributions}

SGQ conceived and designed the study. SGQ and HQC performed this study, HQC and DML extracted the data, SGQ analyzed the data. SGQ, HQC and DML participated in the writing of this paper. All authors have read and approved this manuscript.

\section{Acknowledgements}

We would thank the doctors in the clinical laboratory department of Fangshan Branch of Beijing Nuclear Industry Hospital for providing the clinical test data.

\section{Competing interests}

The authors declare that that they have no competing interests.

\section{References}


1. Jian-gao F. Guidelines for management of nonalcoholic fatty liver disease: an updated and revised edition[J]. Zhonghua Gan Zang Bing Za Zhi. 2010;18(3):163-6.

2. Chalasani N, Younossi Z, Lavine JE, et al. The diagnosis and management of non-alcoholic fatty liver disease: practice Guideline by the American Association for the Study of Liver Diseases, American College of Gastroenterology, and the American Gastroenterological Association[J]. Hepatology. 2012;55(6):2005-23.

3. Loomba R, Sanyal AJ. The global NAFLD epidemic[J]. Nat Rev Gastroenterol Hepatol. 2013;10(11):686-90.

4. Fan JG. Epidemiology of alcoholic and nonalcoholic fatty liver disease in China[J]. J Gastroenterol Hepatol. 2013;28(Suppl 1):11-7.

5. Anderson EL, Howe LD, Jones HE, et al. The Prevalence of Non-Alcoholic Fatty Liver Disease in Children and Adolescents: A Systematic Review and Meta-Analysis[J]. PLoS One. 2015;10(10):e140908.

6. Chan HL, Jia J. Chronic hepatitis B in Asia-new insights from the past decade[J]. J Gastroenterol Hepatol. 2011;26(Suppl 1):131-7.

7. Milic S, Stimac D. Nonalcoholic fatty liver disease/steatohepatitis: epidemiology, pathogenesis, clinical presentation and treatment[J]. Dig Dis. 2012;30(2):158-62.

8. Ekstedt M, Franzen LE, Mathiesen UL, et al. Long-term follow-up of patients with NAFLD and elevated liver enzymes[J]. Hepatology. 2006;44(4):865-73.

9. White DL, Kanwal F, El-Serag HB. Association between nonalcoholic fatty liver disease and risk for hepatocellular cancer, based on systematic review[J]. Clin Gastroenterol Hepatol. 2012;10(12):1342-59.

10. Jiang CM, Pu CW, Hou YH, et al. Non alcoholic steatohepatitis a precursor for hepatocellular carcinoma development[J]. World J Gastroenterol. 2014;20(44):16464-73.

11. Milic S, Lulic D, Stimac D. Non-alcoholic fatty liver disease and obesity: biochemical, metabolic and clinical presentations[J]. World J Gastroenterol. 2014;20(28):9330-7.

12. Kim W. Treatment Options in Non-alcoholic Fatty Liver Disease[J]. Korean J Gastroenterol. 2017;69(6):353-8.

13. Farrell GC, Chitturi S, Lau GK, et al. Guidelines for the assessment and management of non-alcoholic fatty liver disease in the Asia-Pacific region: executive summary[J]. J Gastroenterol Hepatol. 2007;22(6):775-7.

14. Lee SY, Chang HJ, Sung J, et al. The impact of obesity on subclinical coronary atherosclerosis according to the risk of cardiovascular disease[J]. Obesity (Silver Spring). 2014;22(7):1762-8.

15. Wang Z, Hoy WE. Waist circumference, body mass index, hip circumference and waist-to-hip ratio as predictors of cardiovascular disease in Aboriginal people[J]. Eur J Clin Nutr. 2004;58(6):888-93.

16. Wang JG. Chinese Hypertension Guidelines[J]. Pulse (Basel). 2015;3(1):14-20.

17. Chobanian AV, Bakris GL, Black HR, et al. The Seventh Report of the Joint National Committee on Prevention, Detection, Evaluation, and Treatment of High Blood Pressure: the JNC 7 report[J]. JAMA. 2003;289(19):256072.

18. Tuso P. Prediabetes and lifestyle modification: time to prevent a preventable disease[J]. Perm J. 2014;18(3):88-93.

19. Huang Y, Cai X, Chen P, et al. Associations of prediabetes with all-cause and cardiovascular mortality: a metaanalysis[J]. Ann Med. 2014;46(8):684-92.

20. Pan L, Yang Z, Wu Y, et al. The prevalence, awareness, treatment and control of dyslipidemia among adults in China[J]. Atherosclerosis. 2016;248:2-9. 
21. Targher G, Bertolini L, Padovani R, et al. Prevalence of nonalcoholic fatty liver disease and its association with cardiovascular disease among type 2 diabetic patients[J]. Diabetes Care. 2007;30(5):1212-8.

22. Dietrich P, Hellerbrand C. Non-alcoholic fatty liver disease, obesity and the metabolic syndrome[J]. Best Pract Res Clin Gastroenterol. 2014;28(4):637-53.

23. Chalasani N, Younossi Z, Lavine JE, et al. The diagnosis and management of non-alcoholic fatty liver disease: Practice guideline by the American Association for the Study of Liver Diseases, American College of Gastroenterology, and the American Gastroenterological Association[J]. Am J Gastroenterol. 2012;107(6):811-26.

24. Yan J, Xie W, Ou WN, et al. Epidemiological survey and risk factor analysis of fatty liver disease of adult residents, Beijing, China[J]. J Gastroenterol Hepatol. 2013;28(10):1654-9.

25. Fang JG, Zhu J, Li XJ, et al. Epidemiological survey of prevalence of fatty liver and its risk factors in a general adult population of Shanghai[J]. Zhonghua Gan Zang Bing Za Zhi. 2005;13(2):83-8.

26. Liao XH, Cao X, Liu J, et al. Prevalence and features of fatty liver detected by physical examination in Guangzhou[J]. World J Gastroenterol. 2013;19(32):5334-9.

27. Rinella ME. Nonalcoholic fatty liver disease: a systematic review[J]. JAMA. 2015;313(22):2263-73.

28. Zelber-Sagi S, Nitzan-Kaluski D, Halpern Z, et al. Prevalence of primary non-alcoholic fatty liver disease in a population-based study and its association with biochemical and anthropometric measures[J]. Liver Int. 2006;26(7):856-63.

29. Chen ZW, Chen LY, Dai HL, et al. Relationship between alanine aminotransferase levels and metabolic syndrome in nonalcoholic fatty liver disease[J]. J Zhejiang Univ Sci B. 2008;9(8):616-22.

30. Souza MR, Diniz MF, Medeiros-Filho JE, et al. Metabolic syndrome and risk factors for non-alcoholic fatty liver disease[J]. Arq Gastroenterol. 2012;49(1):89-96.

31. Bezerra DS, Faintuch J, Stefano JT, et al. Hypocaloric high-protein diet improves clinical and biochemical markers in patients with nonalcoholic fatty liver disease (NAFLD)[J]. Nutr Hosp. 2014;29(1):94-101.

32. Satapathy SK, Sanyal AJ. Epidemiology and Natural History of Nonalcoholic Fatty Liver Disease[J]. Semin Liver Dis. 2015;35(3):221-35.

33. Brea A, Puzo J. Non-alcoholic fatty liver disease and cardiovascular risk[J]. Int J Cardiol. 2013;167(4):110917.

34. Jacobs EJ, Gapstur SM. Cholesterol and cancer: answers and new questions[J]. Cancer Epidemiol Biomarkers Prev. 2009;18(11):2805-6.

35. Nestel PJ, Mensink RP. Perspective: nonalcoholic fatty liver disease and cardiovascular risk[J]. Curr Opin Lipidol. 2013;24(1):1-3.

36. Nomikos T, Panagiotakos D, Georgousopoulou E, et al. Hierarchical modelling of blood lipids' profile and 10year (2002-2012) all cause mortality and incidence of cardiovascular disease: the ATTICA study[J]. Lipids Health Dis. 2015;14:108.

37. Chalasani N, Younossi Z, Lavine JE, et al. The diagnosis and management of non-alcoholic fatty liver disease: practice guideline by the American Gastroenterological Association, American Association for the Study of Liver Diseases, and American College of Gastroenterology[J]. Gastroenterology. 2012;142(7):1592-609.

\section{Supplementary Files}


This is a list of supplementary files associated with this preprint. Click to download.

- Supplementarymaterials.docx

- TheDataofRiskandPrevalenceofFattyLiverassessed.xIsx 